\title{
Formas atípicas de enfermedad por arañazo de gato, Valdivia
}

\author{
MARITZA NAVARRETE C..$^{1,2}$, MARLIS TÄGER P. ${ }^{3}$, M. SOLEDAD WENZEL A..$^{1,3}$, \\ LORETO PODESTÁ L. ${ }^{3}$, MARITZA PINCHEIRA P. ${ }^{3}$ y LUIS ZAROR C. ${ }^{2}$
}

\section{Atypical presentation of Cat Scratch Disease in Valdivia}

Cat scratch disease (CSD) is the most frequent cause of chronic lymphadenopathy in children and young adults being history of cat or dog contact, scratch or bite in 90 and $60 \%$ of patients respectively. Bartonella infections can course from a lymphadenopathy to a systemic disease. Ten per cent of the patients show atypical presentation and $2 \%$ present severe disease. We present four cases of atypical CSD in children (11 months to 11 years old) in Valdivia, Chile. The etiology was confirmed by IFI IgG against Bartonella henselae, with titles >1: 256.

Key Words: Bartonella henselae, Cat- scratch disease, CSD atypical presentation.

\section{Introducción}

La enfermedad por arañazo de gato (EAG) fue descrita hace más de cuarenta años por Debré, sin embargo su etiología permaneció desconocida hasta los últimos años. Su agente etiológico es la bacteria Bartonella henselae, anteriormente llamada Rochalimaea henselae ${ }^{1}$. El actual género Bartonella resultó de la fusión del género Rochalimaea con la única especie existente del género Bartonella, B. bacilliformis. Los miembros de este género son bacilos Gram (-)s, aeróbicos y de crecimiento fastidioso ${ }^{1,2}$.

La infección con Bartonella spp se manifiesta con un amplio espectro clínico, que va desde una linfoadenopatía a una enfermedad sistémica, afectando tanto a pacientes inmunocompetentes como a inmunodeprimidos ${ }^{3,4}$. En los primeros, la forma clínica de presentación más frecuente es la EAG, mientras que los inmunocomprometidos (SIDA, alcoholismo crónico, entre otros) tienden a tener una presentación sistémica. Sin embargo, ha habido reportes de enfermedad sistémica en pacientes inmunocompetentes, presentándose en 5 a $25 \%$ de los casos como una EAG atípica con diseminación extranodal y compromiso sistémico que da origen a diversas manifestaciones clínicas como compromiso neurológico: encefalitis y encefalopatía, convulsiones, meningitis, mielitis, radiculitis y neuropatía periférica ${ }^{5}$; manifestaciones abdominales: granulomas y microabscesos hepatoesplénicos, hepatitis ${ }^{6,7}$; manifestaciones oculares: retinitis, coroiditis, neuritis óptica y síndrome oculoglandular de Parinaud ${ }^{8}$; manifestaciones óseas: osteítis, osteomielitis, absceso paravertebral y artritis reactiva (meses ${ }^{9-11}$ ).

Bartonella henselae y Bartonella quintana han sido aisladas en pacientes con EAG, aunque se considera que $B$. henselae es responsable de la mayoría de los casos. Clásicamente el diagnóstico de EAG se ha sustentado principalmente en criterios clínicos, epidemiológicos y ocasionalmente histológicos con la presencia de al menos 3 de los siguientes criterios: linfoadenopatía regional con la exclusión de otras etiologías habituales; antecedente de contacto con gato (arañazo y/o mordedura), con o sin lesión de inoculación primaria; test cutáneo positivo para EAG. El tercer criterio ha sido modificado, reemplazado por pruebas serológicas para anticuerpos contra $B$. henselae, siendo la técnica más sensible y específica la IFI. La histopatología característica

Hospital Clínico Valdivia.

Facultad de Medicina, Universidad Austral de Chile:

2 Instituto de Microbiología Clínica.

3 Instituto de Pediatría. 
evidencia una linfadenitis granulomatosa crónica supurada y presencia de bacilos teñidos con la tinción argéntica de Warthin Starry ${ }^{12,13}$.

Presentamos cuatro casos de EAG atípica, diagnosticados inicialmente con criterios clínicoepidemiológicos e histológicos clásicos, y confirmados mediante serología. En todos los casos se realizó estudio serológico por IFI, considerándose evidencia positiva de infección títulos de anticuerpos IgG anti B. henselae > 1: 256.

Caso 1: Lactante menor, sin antecedentes mórbidos de importancia. Dos días previo a su ingreso inició cuadro clínico caracterizado por fiebre, rechazo alimentario, vómitos, tos y coriza, constatándose al examen físico aumento de volumen submandibular izquierdo. Acudió tres días después a la Unidad de Emergencia Pediátrica donde se describió febril, con aumento de volumen submandibular izquierdo que se prolongaba hacia la mejilla y región occipital ipsilaterales, eritematoso y sensible a la palpación. Mientras se realizaba el ingreso presentó una convulsión tónico clónica iniciada en EEII y luego focalizada en el hemicuerpo izquierdo. En el examen segmentario destacaba una erosión antigua en la región frontal. Evolucionó grave, con acidosis metabólica, hiponatrémica, con leucocitosis $\left(17.300 / \mathrm{mm}^{3}\right)$, leve desviación a izquierda, Hto 28,4\%, Hb 9,2 g/dl, VHS $53 \mathrm{~mm} / \mathrm{hr}$, PCR 9,1 mg/dl, LCR: citoquímico normal y tinción de Gram directa sin bacterias. Se inició tratamiento con penicilina sódica, cloxacilina y ceftriaxona. Evolucionó séptico, con falla renal. Una TAC cerebral descartó lesión que explicara el cuadro.

Al tercer día de su hospitalización se describió progresión de aumento de volumen maxilar, comprometiendo las zonas temporal y occipital. Los exámenes de laboratorio sugerían compromiso hepatorenal y bronconeumonía. Se obtuvo dirigidamente el antecedente de la existencia de cinco gatos nuevos en la casa planteándose una EAG. La serología IgG para $B$. henselae fue positiva > 1: 256. Una ecografía con Doppler reveló conglomerado de adenopatías cervicales, aumento difuso de su vascularización y otras adenopatías adyacentes a la región parotídea izquierda y cadena cervical lateral. Se inició tratamiento con claritromicina $15 \mathrm{mg} / \mathrm{kg} /$ día, evolucionando hacia la mejoría con regresión del componente inflamatorio; al alta (20 días post ingreso) persistía un aumento de volumen cervical duro, sensible, sin alteraciones de la piel y que regresó progresivamente hasta comprobarse la resolución total en un control 25 días más tarde.

Caso 2: Paciente de sexo masculino de 13 años. Consultó por cuadro de un mes de evolu- ción, caracterizado por aumento de volumen ganglionar cervical izquierdo de crecimiento rápido asociado a fiebre vespertina, sudoración, decaimiento e inapetencia, sin baja de peso. Dentro de los antecedentes epidemiológicos destacaba el contacto con y rasguños por gatos pequeños. Fue visto en la Unidad de Emergencia donde se consignó un aumento de volumen ganglionar cervical de aproximadamente $5 \mathrm{~cm}$ de diámetro, sensible, sin visceromegalia. Se indicó cloxacilina $100 \mathrm{mg} / \mathrm{kg} /$ día más diclofenaco sódico y se derivó a Consultorio de Hematología Infantil. Se obtuvieron los siguientes exámenes: hemograma normal, VHS $9 \mathrm{~mm} / \mathrm{h}$, perfil bioquímico normal, Rx tórax normal. Serología IgM para Toxoplasma gondii, citomegalovirus y virus Epstein Barr negativas, e IgG para $B$. henselae > 1: 256. Se hospitalizó para estudio. Al examen físico se describía afebril, en buenas condiciones generales, con adenopatía de $5 \mathrm{~cm}$ de diámetro en la región cervical izquierda, sensible y móvil, de consistencia gomosa. No tenía visceromegalias. Una ecografía abdominal mostró imágenes nodulares múltiples hipoecogénicas en el bazo, sugerentes de granulomas esplénicos, con lo que se planteó el diagnóstico de EAG sistémica. Se trató con claritromicina $15 \mathrm{mg} / \mathrm{kg} /$ día durante 14 días, dándose de alta en buenas condiciones.

Se controló al mes encontrándose afebril y con regresión de las adenopatías, VHS 12 mm/h y ecografía abdominal normal.

Caso 3: Paciente de sexo masculino de 12 años, que consultó por cuadro de 6 días de evolución caracterizado por cefalea, fiebre (hasta $39^{\circ} \mathrm{C}$ axilar) artralgia de rodilla derecha y posteriormente de muñeca izquierda. Se hospitalizó con la sospecha de artritis séptica, iniciando antibioterapia que se suspendió a las 48 horas por no tener fundamentación clínica ni de laboratorio.

Dentro de los antecedentes epidemiológicos refería contacto con y mordedura por gato y consumo de leche de vaca no pasteurizada. Al examen físico, el paciente estaba en buenas condiciones generales, eutrófico, consciente, orientado, con leve palidez de piel y mucosas, sin adenopatías periféricas ni visceromegalia, no presentaba puntos óseos sensibles ni limitación de la movilidad articular. El examen neurológico incluyendo fondoscopia era normal. Cicatriz de BCG presente. En los exámenes de laboratorio iniciales destacaban hemograma con recuento de leucocitos normal y neutrofilia, anemia y trombocitosis leve, VHS $106 \mathrm{~mm} / \mathrm{h}$, PCR 19,4 mg/dl, perfil bioquímico normal, examen de orina normal y urocultivo negativo, Rx de tórax, rodilla y muñe- 
ca normales, hemocultivos seriados (automatizados) negativos.

Evolucionó con fiebre persistente, sin foco clínico evidente, catalogándose como síndrome febril prolongado, por lo que se amplió el estudio etiológico. Se solicitaron exámenes inmunológicos: ferritina normal, inmunoglobulinas séricas con aumento de $\operatorname{IgE}(841 \mathrm{IU} / \mathrm{ml}), \mathrm{C} 3$ y C4 normal, ANA, ENA y FR negativo. Se realizó evaluación reumatológica con resultado normal.

Orientando el estudio a etiología infecciosa se realizó PPD: $1 \mathrm{~mm}$, baciloscopías de contenido gástrico (3) negativas, mielocultivo negativo, citoquímico de LCR normal y cultivo negativo, coprocultivo para Yersinia y Campylobacter sin desarrollo, pruebas de aglutinación tíficas, Monotest, título de ASO, ELISA para VIH, reacción de aglutinación para Brucella y Leptospira negativas, IFI IgG $B$. henselae que resultó positiva 1:256, por lo que se solicitó su mayor titulación. Estudio hemato-oncológico: mielograma con hiperplasia granulopoyética leve de médula ósea, marcadores tumorales negativos.

Estudio de imágenes: la ecografía abdominal inicial mostró hepatoesplenomegalia difusa leve y discreta nefromegalia bilateral. Ecocardiograma normal.

Una TAC de abdomen efectuada al mes de evolución presentaba imágenes hepáticas nodulares hipodensas con $2 \mathrm{~cm}$ de diámetro, y en la corteza renal múltiples lesiones hipodensas menor o igual a $0,5 \mathrm{~cm}$ de diámetro. Bazo normal. Fueron interpretadas como granulomas, sugerentes de EAG. La titulación de $\operatorname{IgG} B$. henselae 1: 2048 confirmó el diagnóstico de EAG sistémica con compromiso hepático iniciándose tratamiento con claritromicina $15 \mathrm{mg} / \mathrm{kg} /$ día más rifampicina $20 \mathrm{mg} / \mathrm{kg} /$ día, el que se mantuvo por 14 días. $\mathrm{La}$ curva febril cayó a los 37 días de evolución, con normalización de PCR y descenso de VHS a 50 $\mathrm{mm} / \mathrm{h}$. Fue dado de alta en buenas condiciones generales.

Reingresó a los 14 días por reaparición de compromiso en su estado general y osteomialgias en antebrazo derecho, con curso afebril. Al examen existía dolor en la palpación de carpo y antebrazo derecho. Los exámenes de control mostraban hemograma normal, VHS $50 \mathrm{~mm} / \mathrm{hr}$, perfil bioquímico normal y PCR negativa, cintigrama óseo normal, ecografía abdominal con imágenes hepatoesplénicas hipoecogénicas nodulares, compatibles con microabscesos, riñones normales. Titulación de $\operatorname{IgG}$ para $B$. henselae > 1: 8192 .

El dolor cedió con antiinflamatorios y analgésicos. Se realizó control ambulatorio un mes tras el reingreso, encontrándose en buenas condiciones, examen físico dentro de rangos normales, exámenes de laboratorio con PCR negativa, hemograma normal, VHS $12 \mathrm{~mm} / \mathrm{h}$, y ecografía abdominal normal.

Caso 4: Paciente de sexo masculino de 13 años, presentó un cuadro clínico de una semana de evolución, caracterizado por fiebre (hasta $40^{\circ}$ $\mathrm{C}$, axilar), decaimiento y vómitos. Al examen físico destacaba un dolor abdominal, difuso, sin visceromegalia. El hemograma era normal, VHS $72 \mathrm{~mm} / \mathrm{h}$, PCR 3,3 mg/dl, perfil bioquímico normal, urocultivo negativo. Dentro de los antecedentes epidemiológicos destacaba el contacto permanente con gatos pequeños. Evolucionó febril (14 días) realizándose el siguiente estudio tendiente a esclarecer su cuadro clínico: pruebas de aglutinación tíficas negativas, hemocultivos negativos, ELISA para VIH negativa, estudio imagenológico (Rx de tórax, Rx de senos paranasales) normal, ecotomografía abdominal con esplenomegalia leve, C3 y C4, ferritinemia e inmunoglobulinas séricas normales, factor reumatoideo negativo, baciloscopias de contenido gástrico (3) y orina (6) negativas, serología IgM para $T$. gondii y CMV negativas. Por persistir con un síndrome febril prolongado se solicitó evaluación oftalmológica, la fondoscopia reveló retinocoroiditis y microgranulomas retinales (en número de 6) en el ojo derecho, sin defectos visuales. Una TAC cerebral fue normal. Se planteó EAG con compromiso ocular, obteniéndose una IFI IgG para B. henselae > 1: 1.024 confirmatoria del diagnóstico. Se inició tratamiento antimicrobiano con claritromicina $15 \mathrm{mg} / \mathrm{kg} /$ día más rifampicina $20 \mathrm{mg} / \mathrm{kg} /$ día recibiéndolos durante 14 días. El control oftalmológico un mes después demostraba regresión completa de los microgranulomas retinales.

\section{Discusión}

La EAG es transmitida al hombre por arañazo o mordedura de un gato Diversos estudios muestran que los gatos, especialmente los animales jóvenes, son el reservorio natural de $B$. henselae y su rol en la transmisión de la enfermedad está bien determinado ${ }^{1}$. Estos felinos son asintomáticos y no muestran evidencia de la enfermedad ${ }^{14}$. Los gatos adquieren la infección de pulgas y garrapatas. El hábito de estos felinos de lamerse, mantiene la bacteria en su pelaje, saliva y garras. Cuando éste rasguña o muerde a una persona, la bacteria pasa a ella a través de sus uñas y saliva. También puede provocar infección ocular si es 
que se ha acariciado la piel del gato y luego se frota los ojos con la misma mano ${ }^{14}$.

Desde la asociación de Bartonella spp con angiomatosis bacilar y fiebre con bacteriemia, bacterias de este género han sido implicadas en infección humana con diversas formas de presentación clínica. Entre éstas se encuentran serias complicaciones como endocarditis y lesiones de casi todos los órganos como, corazón, hígado, bazo, hueso, médula ósea, linfáticos, músculos, tejido blando y $\mathrm{SNC}^{15-17}$.

La EAG está considerada como la causa más frecuente de linfoadenopatía benigna crónica en niños y adolescentes $(80 \%$ bajo 21 años de edad $^{3,10}$. La presencia de linfoadenopatías regionales es la característica clínica predominante, siendo las localizaciones más frecuentes axilar, cervical y submandibular, aunque es posible la afectación ganglionar generalizada. Las adenopatías son blandas y ocasionalmente se abscedan. Los cambios histológicos del nodo linfático son hiperplasia linfoide, formación de un granuloma, desarrollo de abscesos y en algunos casos supuración ${ }^{18}$. Durante el curso clínico puede aparecer fiebre, malestar general, cefalea, anorexia, vómitos, artralgias, exantema, eritema nodoso, púrpura trombocitopénico y esplenomegalia. En $\sim 10 \%$ de los casos ocurren manifestaciones atípicas y aproximadamente $2 \%$ presenta complicaciones graves. Las complicaciones de EAG son síndrome oculoglandular de Parinaud, manifestación atípica común (2 a 17\% de los pacientes), abscesos hepáticos y esplénicos con resolución lenta de dos a tres meses, manifestaciones neurológicas como encefalopatía, compromiso de nervios craneanos y periféricos, encefalitis, meningitis y mielitis ( 1 a $7 \%$ de los casos). La encefalopatía es más frecuente en niños entre 7 y 12 años, manifestándose con fiebre (50\%), convulsiones (40-50\%). Otras complicaciones han sido descritas, como compromiso oftálmico, neumonía, efusión pleural $(0,2 \%)$, osteomielitis de cualquier hueso $(0,3 \%)$. Generalmente se resuelve espontáneamente en 4 a 20 meses $^{1,9}$.

En nuestra serie clínica observamos un lactante menor con compromiso encefálico y convulsiones tónico clónicas, un paciente presentó compromiso ocular con retinocoroiditis y microgranulomas, y dos pacientes desarrollaron granulomas hepatoesplénicos con resolución dentro del período esperado.

El compromiso hepatoesplénico ocurre cuando $B$. henselae causa granulomas necrozantes en el bazo o en el hígado. Se han sugerido varias formas de transmisión de la infección a estos órganos, pero dado que este microorganismo ha sido aislado de sangre, la vía más probable es hematógena. El compromiso visceral debe sospecharse en pacientes cuya enfermedad curse con síndrome febril prolongado, dolor abdominal o compromiso sistémico, aun en ausencia de adenopatía periférica y/o anormalidades hepáticas clínicas o bioquímicas. La ecografía abdominal y/o TAC abdominal demuestran múltiples áreas hipoecogénicas o hipodensas redondeadas, ovaladas o irregulares, que miden desde $3 \mathrm{~mm}$ a $3 \mathrm{~cm}$, y que se resuelven o calcifican en un período variable de semanas a meses ( 4 semanas a 19 meses $)^{20}$.

Los exámenes de laboratorio generales no constituyen un aporte significativo para el diagnóstico de la EAG. El hemograma no parece ser un examen que permita diferenciar esta enfermedad de otras causas de linfoadenopatías. Se observa también que la VHS tiene alta variabilidad, fluctuando entre 9 - $106 \mathrm{~mm} / \mathrm{h}$ en los pacientes analizados. Abarca et al en 1996 presentaron una serie clínica de 10 casos en pacientes entre 6 y 13 años, donde la mitad de estos tuvo VHS mayor $50 \mathrm{~mm} / \mathrm{h}$.

En nuestro estudio el diagnóstico se fundamentó en las manifestaciones clínicas, antecedentes epidemiológicos, la exclusión de otros agentes infecciosos y la confirmación con serología positiva para $B$. henselae $>1: 256$. El CDC de Atlanta - E.U.A., establece títulos de anticuerpos IgG mayores a 1:64 como evidencia positiva de infección por $B$. henselae, test específico para género (93-96\%), pero no claramente definido para especie, dada la existencia de reacciones cruzadas $^{1,3,21}$. Estudios recientes señalan como títulos confiables aquellos > 1: 512 en poblaciones con una alta seroprevalencia, recomendando el seguimiento evolutivo de la curva serológica ${ }^{22}$. En nuestra serie todos los pacientes mostraron serología IgG para B. henselae > 1: 256; en dos de ellos se realizó titulación, siendo uno de ellos > 1: 1024 y el segundo caso con un título > 1:8.192.

En el huésped inmunocompetente la EAG se considera un proceso autolimitado que sigue un curso benigno hasta la curación, que remite espontáneamente en dos a seis meses. Pocos casos requieren hospitalización, por lo que el tratamiento antimicrobiano de la EAG clásica en estos pacientes es controversial. En el huésped inmunocomprometido en cambio, se ha observado una respuesta clara y a veces espectacular a la terapia antimicrobiana. Se recomienda manejo sintomático para los pacientes con cuadros leves y en el caso de utilizar antimicrobianos se ha reportado éxitos terapéuticos con fármacos que alcanzan 
alta concentración tisular como eritromicina, claritromicina o azitromicina, administrados durante 14 días. En casos de enfermedad complicada, diseminada o atípica se recomienda utilizar ciprofloxacina, gentamicina o macrólidos asociados a rifampicina ${ }^{1,19}$.

Con los conocimientos actuales es conveniente considerar la infección por $B$. henselae como una zoonosis probablemente frecuente en la población, cuya expresión clínica difiere según el estado inmunitario del individuo infectado. Dado que la infección por $B$. henselae está presente en nuestro medio como una etiología de linfoadenopatía regional, debe ser considerada en el diagnóstico diferencial de estos cuadros, investigando dirigidamente los antecedentes de contacto, rasguño y/o mordedura de gato $\mathrm{y}$, tener presente que la EAG diseminada puede presentarse como un síndrome febril prolongado, en ausencia de linfoadenopatía periférica ${ }^{23}$.

\section{Resumen}

La enfermedad por arañazo de gato (EAG), es considerada la causa más frecuente de linfoadenopatía benigna crónica en niños y adolescentes. En los casos existe el antecedente de contacto con gatos $(90 \%)$ y de rasguño y/o mordedura $(60 \%)$. La infección con Bartonella spp se manifiesta como desde una linfoadenopatía (EAG) a una enfermedad sistémica. El $10 \%$ tiene manifestaciones atípicas y $2 \%$ presenta complicaciones graves. Debe sospecharse EAG por exclusión de otras etiologías habituales y por el antecedente epidemiológico de contacto y/o rasguño de gato, con o sin lesión de inoculación primaria.

Se presentan 4 casos de EAG atípicas en niños del S.S. Valdivia, donde se confirmó el agente por IFI IgG contra Bartonella henselae, con títulos > 1: 256.

\section{Bibliografía}

1.- Anderson B, Neuman M. Bartonella spp. as emerging human pathogens. Clin Microbiol Rev 1997; 203-19.

2.- Lucy D, Dolan J, Moss C W et al. Relaping illness due to Rochalimeae henselae in immunocompetent hosts: implication therapy and new epidemiological associations. Clin Infect Dis 1992; 14: 683-8.

3.- Bass J, Vincent J, Person D. The expanding spectrum of Bartonella infections: II. Cat-scratch disease. Pediatr Infect Dis J 1997; 16: 163-79.

4.- Holmes A, Greenough T, Balady G et al. Bartonella henselae endocarditis in an immunocompetent adult.
Clin Infect Dis 1995; 21:1004-7.

5.- Hahn J, Sum J, Lee P. Unusual MRI findings after status epilepticus due to cat-scratch disease. Pediatr Neurol 1994; 10 (3): 255-8.

6.- Dunn M, Berkowitz F, Miller J, Snitzer J. Hepatosplenic cat scratch disease and abdominal pain. Pediatr Infect Dis J 1997; 16: 269-72.

7.- Estrada B, Silio M, Begue R, Van Dyke R. Unsuspected hepatosplenic involvement in patients hospitalized with cat-scratch disease. Pediatr Infect Dis J 1996; 15 (8): $720-1$.

8.- Ormerod D, Scolnick K, Menosky M, Pavan R, Pon D. Retinal and choroidal manifestations of cat-scratch disease. Ophthalmology 1998; 105 (6): 1024-31.

9.- Wolff E, Muñoz M P, Zapata C y Ledermann W. Enfermedad por arañazo de gato complicada con compromiso sistémico, osteomielitis osteovertebral y absceso paravertebral. Rev Chil Infect 2000; 17 (4): 332-9.

10.- Täger $\mathrm{M}$ y Zamorano J. Osteomielitis, una manifestación inusual de la enfermedad por arañazo de gato. Rev Chil Infectol, 2000;17 (4): 326-31.

11.- Ladron De Guevara D, Lobo G, Miranda M et al. Forma atípica de enfermedad por arañazo de gato: Compromiso óseo en dos pacientes pediátricos detectado mediante cintigrafía ósea. Revisión de la literatura. Rev Chil Infect 2003; 20 (3): 202-9.

12.- Margileth A M. 1995. Sorting out the causes of lymphadenopathy. Contemp Pediatr 12: 23-40.

13.- Abarca K. Enfermedad por arañazo de gato. Rev Chil Infect 1996; 13 (2): 78-80.

14.- Booras C H. 1997. Cat scratch disease. http://www. jaxmes.com/cat seratch.htm.

15.- Slater L N, Wech D F, Hensels D, Coody D W. A newly recognized fastidious Gram-negative pathogen as a caused of fever and bacteremia. N Engl J Med 1990; 322: 1587-93.

16.- Jackson L A, Perkins B A, Wenger D. Cat scratch disease in the United States: an analysis of three national databases. Am J Public Health 1993; 83: $1707-$ 1711.

17.- Abarca K, Vial P, Rivera M et al. Infección por Bartonella henselae en pacientes inmunocompetentes: Enfermedad por arañazo de gato. Rev Méd Chile 1996; 124 (2): 78-80.

18.- Simó J, Riquelme D, Anda P. Enfermedad por arañazo de gato: descripción de un nuevo caso. Enferm Infecc Microbiol Clin 1998; 16 (6): 291-2.

19.- Dehio C, Sander A. Bartonella as emerging pathogens. Trends in Microbiology 1999; 7 (6): 226-8.

20.- Larsen C, Patrick L. Abdominal (liver, spleen) and bone manifestations of cat- scratch disease. Pediatr Radiol 1992; 22: 353-5.

21.- Aguirrebangoa K, Benito J R, Montejo M, Bereciartua E, Pérez-Irezabal J, González-Zárate P. Enfermedad por arañazo de gato: serie de 14 casos. Utilidad diagnóstica de la serología. Enferm Infecc Microbiol Clin 1999; 17: $15-8$.

22.- Spach D, Koehler J. Bartonella - associated infections. Infect Dis Clin North Amer 1998; 12 (1): 137-55.

23.- Jacobs R F, Schutze G E. Bartonella henselae as a cause of prolonged fever and fever of unknown origin in children. Clin Infect Dis 1998; 26: 80-4.

Correspondencia a:

Maritza Navarrete Contreras

E-mail: maritzanavarrete@uach.cl 